\title{
Hooked on fishing? Recreational angling interactions with the Critically Endangered grey nurse shark Carcharias taurus in eastern Australia
}

\author{
William D. Robbins ${ }^{1,2, *}$, Victor M. Peddemors ${ }^{1,4}$, Matt K. Broadhurst ${ }^{3}$, Charles A. Gray ${ }^{1}$ \\ ${ }^{1}$ Cronulla Fisheries Research Centre of Excellence, NSW Department of Primary Industries, Cronulla, New South Wales 2230, \\ Australia \\ ${ }^{2}$ Wildlife Marine, Perth, Western Australia 6020, Australia \\ ${ }^{3}$ Fisheries Conservation Technology Unit, NSW Department of Primary Industries, Coffs Harbour, New South Wales 2450, \\ Australia \\ ${ }^{4}$ Present address: Fisheries NSW at Sydney Institute for Marine Science, Mosman, New South Wales 2088, Australia
}

\begin{abstract}
The grey nurse shark Carcharias taurus is critically endangered in eastern Australia. Although fully protected, instances of recreational hooking persist in this population, with potentially fatal consequences. Here we used in situ underwater video to quantify the rates at which $C$. taurus interacts with a range of proximately deployed recreational fishing gears, and we suggest appropriate management changes to limit such interactions. Bottom-set baits elicited strong responses, with 15 to $43 \%$ of whole and filleted mackerel baits depredated within 5 min. Smaller Australian sardine (pilchard) and squid baits were taken by C. taurus at a significantly lower, yet appreciable rate of 3 to $15 \%$. These smaller baits were depredated more by recreationally important teleosts, although this relationship was not significant for sardine baits. There was no consistent diel influence on shark bait depredation, although $C$. taurus was the only nocturnal bait depredator. Trolled gears posed no direct threat to C. taurus at any time, even when trolled at depth. Benthic-oriented jigs were rarely snapped at by $C$. taurus, yet may still pose a foul-hooking risk as sharks showed a propensity to rub against these jigs at depth. Vertical jigs elicited little response by $C$. taurus, although foul-hooking was also a risk as jigs contacted sharks in $5 \%$ of proximate drops, with near misses or line-only interactions occurring in a further $6 \%$ of cases. Our findings suggest that restricting bottom-set baits and benthic-oriented gears such as jigs around C. taurus aggregations would be a feasible and enforceable strategy to minimise recreational fishing interactions.
\end{abstract}

KEY WORDS: Recreational fishing - Hooking - Gear selectivity - Angling bycatch reduction · Sand tiger shark $\cdot$ Ragged-tooth shark

Resale or republication not permitted without written consent of the publisher

\section{INTRODUCTION}

Marine predators such as sharks invariably hold elevated positions in the trophic web (Cortés 1999). Sharks are consequently often relatively low in abundance, with conservative life histories. Although some sharks can absorb increased levels of mortality
(Smith et al. 1998, Walker 1998, Takeuchi et al. 2005), numerous populations around the globe show systematic declines, invariably attributed to overfishing (Myers \& Worm 2003, Ward \& Myers 2005, Robbins et al. 2006, Worm et al. 2006).

Minimising the unwanted capture of sharks has both ecological and economic benefits, especially for 
larger-bodied species. The loss of large sharks can have severe top-down effects, markedly impacting the abundance and biodiversity of lower-trophic order species (Stevens et al. 2000, Bascompte et al. 2005, Myers et al. 2007). The resultant changes can have deleterious economic consequences for the fishing and tourism industries, even those targeting unrelated species (Anderson \& Ahmed 1993, Myers et al. 2007). With generation times often on the order of decades, the effects of shark depletions can be long-lasting, even if the original pressure is removed (Stevens et al. 2000).

One large shark species that has suffered severe population declines is the grey nurse shark Carcharias taurus. Also known as the sand tiger or ragged-tooth shark, this coastal species inhabits sub-tropical to temperate shallow rocky areas in the Atlantic and western Indian and Pacific Oceans (Compagno 2001). In eastern Australia, its accessibility and benign behaviour make it an iconic species with marine tourism (Barker et al. 2011); however, the same habitat choice also exposes C. taurus to recreational line fishing targeting popular teleosts such as snapper Pagrus auratus and yellowtail kingfish Seriola lalandi.

Carcharias taurus has demographic characteristics which allow little capacity to absorb additional mortality: the species matures late, retains only 1 embryo per uterus, and requires 2 to 3 yr between breeding cycles (Lucifora et al. 2002, Otway et al. 2004, Bansemer \& Bennett 2009). Consequently, C. taurus is particularly susceptible to even low levels of exploitation (Bradshaw et al. 2008). The eastern Australian population was targeted during the 1950s and 1960s (Cropp 1964), due to the belief that the species was responsible for local shark attacks. However, attitudes have since shifted and are now dominated by concern for the viability of the remaining population. The eastern Australian population was listed as 'endangered' in 2000 due to its low abundance and was further listed as 'critically endangered' in 2002 under the Australian Federal Environmental Protection and Biodiversity Conservation Act of 1999.

Abundance estimates of Carcharias taurus suggested that as few as 410 to 766 individuals remained in the eastern Australian population when they were listed as critically endangered (Otway \& Burke 2004). As part of a recovery plan, the New South Wales (NSW) government responsible for managing the majority of the eastern Australian C. taurus range implemented modified fishing regulations at 10 recognised $C$. taurus aggregation areas. Known as 'critical habitats', the modified fishing regulations prohibited fishers from anchoring or mooring while bait fishing, and restricted the use of wire trace or baits $>500 \mathrm{~g}$ (DPI 2007).

Critical habitats are designed to provide an important refuge for Carcharias taurus, but the degree to which these restrictions have reduced or eliminated incidental shark hooking remains unknown. It is well established that many Australian C. taurus incur external hooking or fishing-related damage, which is often first documented within NSW critical habitats (Bansemer \& Bennett 2010). Moreover, examinations of tagged $C$. taurus within critical habitats showed $25 \%$ of individuals incurring hook damage within 1 yr of tagging (Otway \& Burke 2004). However, owing to daily and seasonal migrations (Bruce \& Stevens 2002, Otway \& Burke 2004, Lincoln Smith \& Roberts 2010), the extent to which such injuries are sustained within critical habitat boundaries remains unclear.

Light recreational fishing gear has been identified as the primary cause of Carcharias taurus fishing interactions (Bansemer \& Bennett 2010); however, the levels of risk that different gear types pose is unknown. This study aimed to address the lack of relevant knowledge by determining the response of C. taurus to common recreational fishing gears. Using methods permitted within NSW critical habitats, 3 specific fishing configurations were investigated: (1) benthic-orientated baits, (2) horizontally towed attractants (trolled lures) and (3) vertically deployed attractants (jigs). Our aim was to determine the relative risk each gear type poses to $C$. taurus when used proximate to their aggregations.

\section{MATERIALS AND METHODS}

\section{Study site and equipment}

Sampling took place at Fish Rock, on the east Australian coast $\left(30.937^{\circ} \mathrm{S}, 153.101^{\circ} \mathrm{E}\right.$; Fig. 1A). This is a small, uninhabited rocky island complex, approximately 2 nautical miles offshore. The area around Fish Rock is designated a critical habitat and is one of the few year-round aggregation sites for Carcharias taurus (Bansemer \& Bennett 2010). The area is also recreationally fished, primarily for the pelagic Seriola lalandi.

Fieldwork took place from dawn through the night between October 2009 and November 2010, using a $5.7 \mathrm{~m}$ vessel. Sampling followed recreational line fishing activities permitted in critical habitats, and all treatments tested were witnessed in active use by recreational fishers at the sampling area. Hooks were disabled on all gears to prevent captures. Instead, 

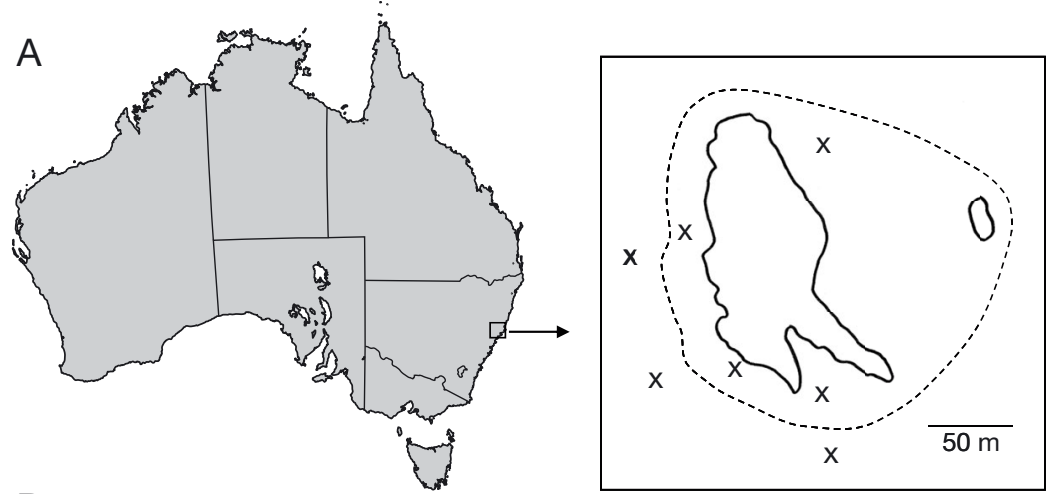

B

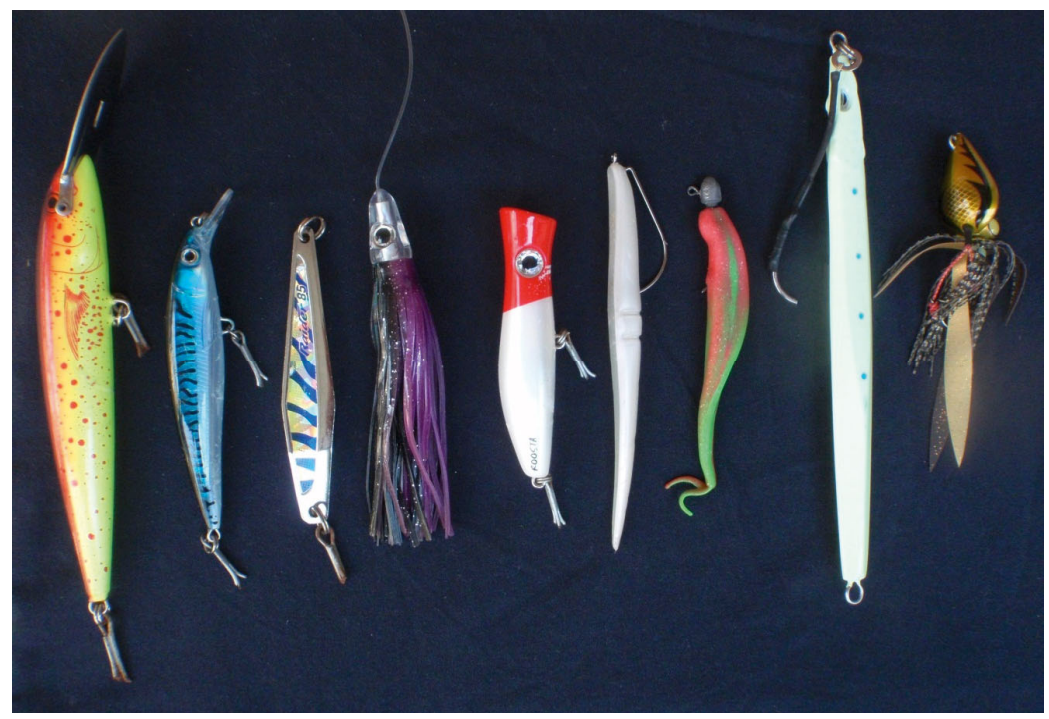

Fig. 1. (A) Study site at Fish Rock, a small, uninhabited rocky island complex offshore of New South Wales, Australia. Dashed line indicates approximate path taken during horizontally towed lure trials; $(\mathrm{X})$ : positions where bait and jig trials were undertaken. (B) Examples of the gear configurations tested for towing and jigging trials. Shown (left to right) are 2 hard plastic lures, a metal lure, a feather jig, a popper, a trolled soft plastic, a soft plastic vertical jig, a knife jig and a benthic-oriented jig

fish and shark interactions were monitored primarily using a $12 \mathrm{~V}$ Seaviewer ${ }^{\mathrm{TM}}$ underwater video camera deployed from the vessel. This system transmitted signals along a cable in real time, allowing video to be observed from the vessel and recorded for later analysis. The physical presence and electronic signature of this camera has no effect on the behaviour of wild sharks (Robbins et al. 2011). For logistical reasons, a much smaller, inline GoPro ${ }^{\mathrm{TM}}$ HD Hero underwater video camera was used to record vertical jig trials. We believe this camera also had no effect on the sharks, since it was much smaller in size (approximately $1 / 5$ the size of the Seaviewer ${ }^{\mathrm{TM}}$ camera) and power (3.7 V internal battery). Moreover, this camera did not externally transmit any signal.

\section{Benthic-oriented baits}

Bait trials were conducted using a paternoster rig, a common benthic fishing method around rugous substrates. The rig had a sinker weight at the end of the fishing line, with the bait suspended a short distance above. We floated the baits on a $50 \mathrm{~cm}$ length of monofilament line leading off the main line to minimise the risk of Carcharias taurus inadvertently ingesting sinker weights during bait depredation. Baits were positioned 70 to $100 \mathrm{~cm}$ above the substrate, with the camera suspended 3 to $4 \mathrm{~m}$ above. Two red-filtered lights were used at night to illuminate the area immediately surrounding the baits. Four bait types were tested: (1) whole and (2) half fillet of blue mackerel Scomber australasicus; (3) whole Australian sardine Sardinops sagax, locally referred to as 'pilchard'; and (4) whole squid Loligo sp. The blue mackerel baits measured approximately $29 \mathrm{~cm}$ in length, with the smaller squid and sardine baits measuring around 17 and $10 \mathrm{~cm}$ long, respectively. All baits met the legal weight restriction of critical habitat areas, with the heaviest bait (whole blue mackerel) weighing approximately $350 \mathrm{~g}$.

Trials consisted of $5 \mathrm{~min}$ replicates conducted typically in sandy gutters within $40 \mathrm{~m}$ of Carcharias taurus aggregations. The daily positions of aggregations were identified through video camera deployment and reports from dive boat operators. At all positions where trials were conducted, recreational fishing was observed at various times throughout this study (Fig. 1A). Sampling was conducted over 5 discrete time periods: dawn, morning, afternoon, dusk and night. Dawn and dusk time periods lasted 1.0 to $1.5 \mathrm{~h}$, with morning and afternoon periods lasting 1.5 to $2.5 \mathrm{~h}$, depending on the season. All sampling time periods were separated by an interval of at least $1 \mathrm{~h}$. Dawn sampling began at first light, and dusk ended with the last light of the day. Bait order was randomised, with each daytime sampling period consisting of no more than 10 replicates of any bait type, up to a maximum of 25 replicates. This ensured that multi- 
ple attractants were tested per time period each day. Night sampling was conducted within $60 \mathrm{~m}$ of the position in which sharks had aggregated that day. A maximum of 40 replicates were conducted across any single night, with a 30 to 60 min interval between bait types. A strike was recorded when a shark or fish took a bait, or completely engulfed it in its mouth. Replicates were repeated if the bait was dislodged or lost. To reduce the confounding variable of bait freshness, baits were replaced after 3 replicates if not taken.

\section{Horizontally towed lures}

Artificial lures were individually towed (trolled) $24 \mathrm{~m}$ behind the boat, in a circuit around the Fish Rock complex (Fig. 1A). A series of exploratory SCUBA dives repeatedly revealed stray Carcharias taurus individuals outside conspecific aggregations; thus this circuit was deemed to maximise exposure of the gear to both high and low shark densities. Fifteen different artificial lures of varying composition, colour and size were tested: rattling plastic (blue, blue/silver, green/blue and silver); non-rattling plastic (blue/white, red/white, yellow/green and yellow/ red); metal (silver); soft plastic (white and green/ orange); plastic 'poppers' which skim the water surface (red/white and blue/silver) and soft 'feather jigs' (red/white and purple/black) (Fig. 1B). A whole blue mackerel bait was also trolled using the same methods.

Tows were conducted at dawn, and in the morning and afternoon only, as no recreational trolling was observed at dusk or at night. Depending on the lure, replicates were trolled either shallow $(0-2 \mathrm{~m})$ or deep $(7-10 \mathrm{~m})$, at 4 to 7 knots, following manufacturer recommendations. Track speeds were monitored using a GPS. The video camera was towed 3 to $4 \mathrm{~m}$ in front of the lures, facing aft to record interactions. Lead weights were added to the camera to orientate it at the required depths.

\section{Vertically deployed jigs}

Two configurations of vertically deployed jigs were investigated. The first involved the standard method of jigging, where the jig was dropped via rod-and-reel to the substrate before being immediately retrieved in a rapid, jerking motion. Due to difficulties keeping the moving jig within the Seaviewer $^{\mathrm{TM}}$ camera field of view, video of these trials was recorded using a GoPro ${ }^{\mathrm{TM}}$ HD Hero camera attached inline $1 \mathrm{~m}$ above the jig. This configuration allowed the lure to maintain a constant position in the camera field of view as it was deployed and retrieved, although it prevented real-time viewing of results. Two types of metal jigs (pink and green 'knife' jigs) and 4 types of soft plastics (blue, brown/ white, green/orange and white) were tested during morning and afternoon sampling (Fig. 1B). Dawn, dusk and night were not sampled due to logistical constraints, or to these activities not being observed to occur at these times.

The second jig configuration examined was one used to target benthic fishes such as Pagrus auratus (Fig. 1B). These benthic-oriented jigs are designed to be dropped to the substrate, and either slowly retrieved or held stationary. In this experiment, the jig was deployed 3 to $4 \mathrm{~m}$ below the Seaviewer ${ }^{\mathrm{TM}}$ camera, and held 70 to $100 \mathrm{~cm}$ off the substrate, as per the bait trials. Two colours (gold and pink) of jigs were tested at dawn, and in the morning and afternoon.

\section{Data collected and analyses}

Analysis of trials was conducted by reviewing video footage in the laboratory. For baits and benthic-oriented jigs, the following data were recorded for each replicate: (1) fate of the bait; (2) time to take the bait (if applicable); (3) maximum number of Carcharias taurus observed onscreen, or the number of identifiable individuals (whichever was greater); (4) number of $C$. taurus approaches within $\sim 1 \mathrm{~m}$ of the bait; and (5) number of $C$. taurus random interactions with the bait (where the bait drifted within $\sim 1 \mathrm{~m}$ of the anterior half of the shark or touched any part of the shark). For the towed gears, the number of successful fish and $C$. taurus strikes, and the number of fish and shark reactions (chases of the lure, or changes in movement or direction) were also recorded. In the vertical jig trials, we recorded: (1) proportion of jigs landing within the immediate area (within the same gutter as the sharks); (2) proportion of jigs landing within an estimated body length of any C. taurus; (3) reactions of the sharks to the jigs; and (4) number of jig or line contacts with sharks.

Data were pooled across the sampling period. A generalised linear model was run in R 2.14 to investigate the effects of time of day and bait type on bait depredation rates (R Development Core Team 2012). Terms were sequentially added, and analysed using an analysis of deviance table. The model used a logit link function, with binomial outcome (bait taken or 
not). Analyses were then re-run with the terms added in reverse order, as well as with the non-significant interaction term removed; however, neither analysis altered the findings.

Chi-squared tests were used to examine recreationally important teleost takes using an online calculator (Preacher 2001). An ANOVA was conducted using SPSS 17 to determine the effect of time of day on time to depredate baits. Here, data were $\ln (x+1)$ transformed to remove heteroscedasticity following a Levene's test. Further chi-squared tests were performed on the strike rates of teleosts on towed attractants. In all cases, the null hypotheses were rejected at $\mathrm{p}<0.05$. Standard errors (SE) of bait depredation rates were manually calculated using the formula:

$$
\mathrm{SE}=\sqrt{\frac{p \times(1-p)}{\mathrm{n}-1}}
$$

where $p$ is the proportion of baits depredated, and $\mathrm{n}$ is the number of baits deployed.

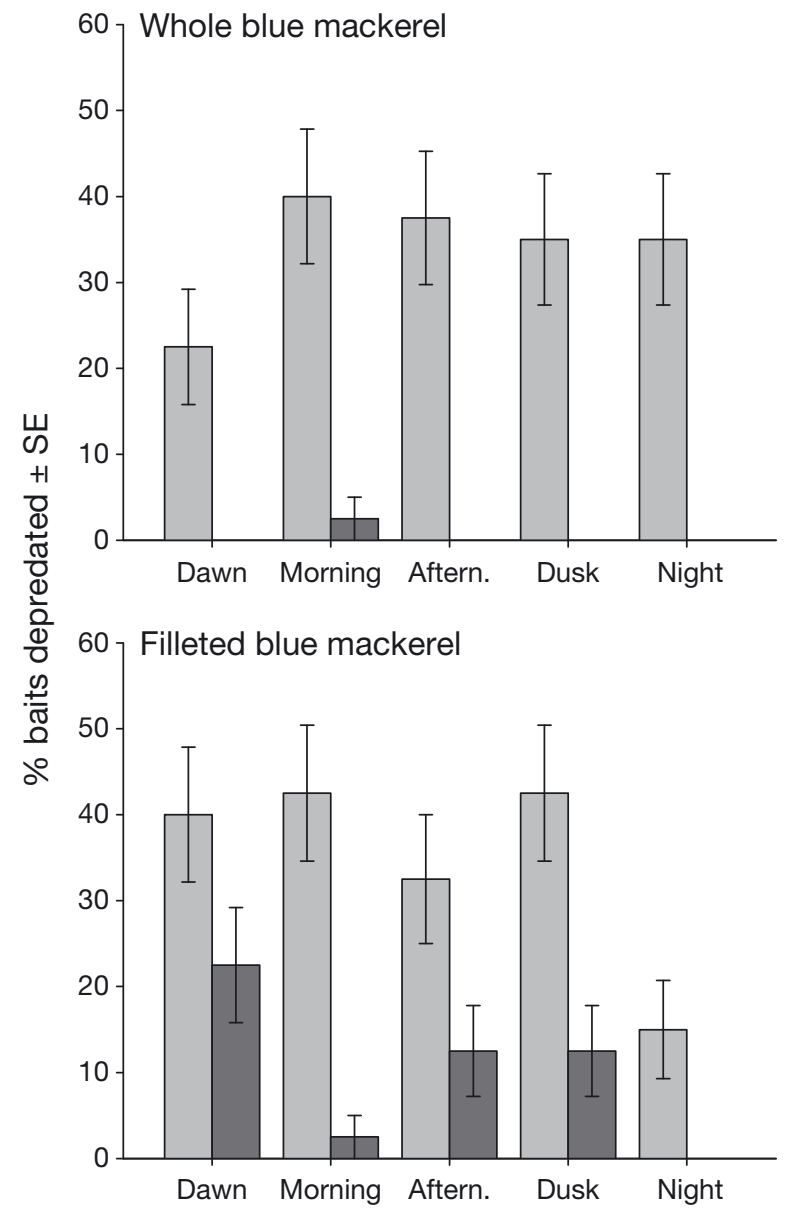

\section{RESULTS}

\section{Benthic baits}

Two hundred replicates were conducted for each bait type, distributed equally across the 5 sampling periods. Blue mackerel baits were favoured by Carcharias taurus, being depredated at rates of 23 to $40 \%$ (whole) and 15 to $43 \%$ (filleted; Fig. 2). Smaller sardine and squid baits were taken significantly less often, but still at appreciable rates of 5 to $15 \%$ (sardine) and 3 to $15 \%$ (squid). Although the depredation rate of all baits was reduced at either dawn or night, this decrease was not significant (Table 1).

Baits were also depredated by recreationally important teleosts, although these occurred during daylight hours only (Fig. 2). Seriola lalandi was responsible for $69 \%$ of depredations, together with serranids, sparids and other carangids. Significantly fewer whole
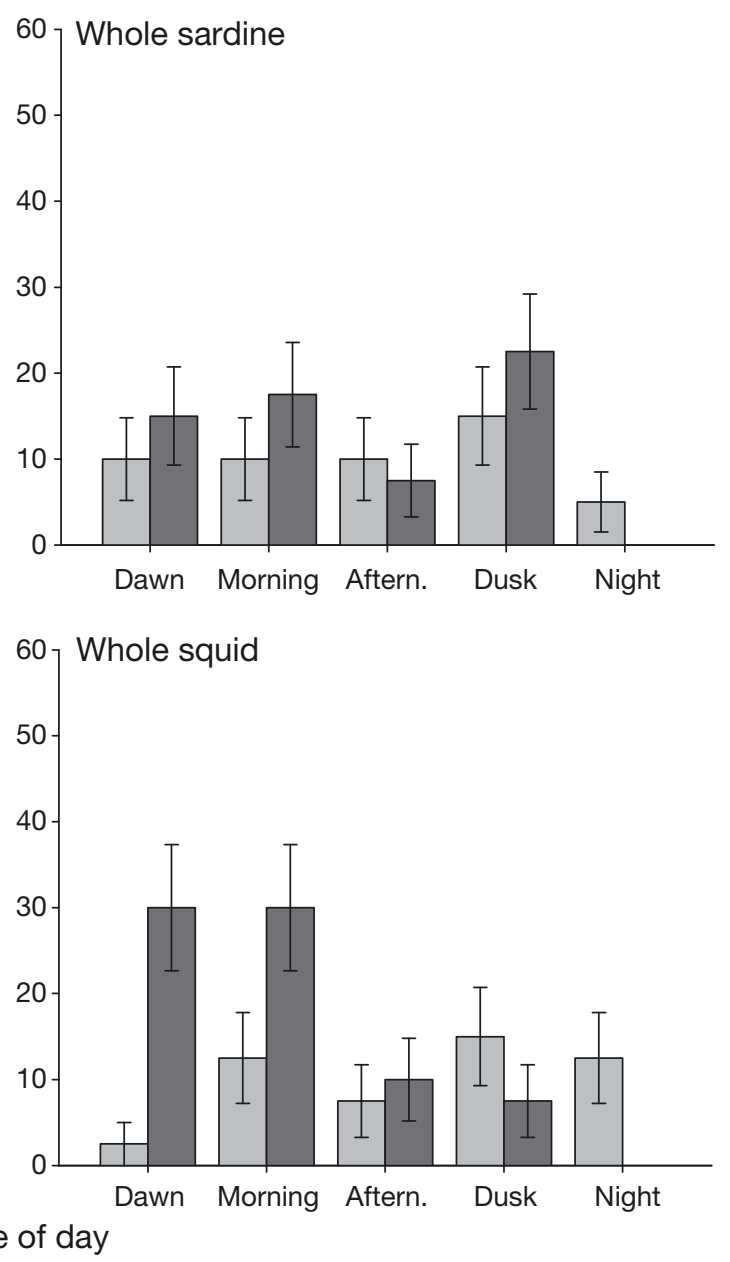

Fig. 2. Bait depredations by Carcharias taurus (light grey) and recreationally important fishes (dark grey) across time of day 
Table 1. Carcharias taurus. Analysis of deviance examining bait depredations by grey nurse sharks at Fish Rock, New South Wales, Australia

\begin{tabular}{|lrccc|}
\hline Factor & Deviance & df & $\begin{array}{c}\text { Residual } \\
\text { deviance }\end{array}$ & $\mathrm{p}$ \\
\hline Time of day (TOD) & 7.348 & 4 & 838.23 & 0.119 \\
Bait & 72.064 & 3 & 766.16 & $<0.0001$ \\
Bait $\times$ TOD & 13.472 & 12 & 752.69 & 0.336 \\
\hline
\end{tabular}

and filleted blue mackerel baits were taken by recreationally important teleosts than by Carcharias taurus during daylight hours $\left(\chi^{2}=51.07, \mathrm{df}=1, \mathrm{p}<\right.$ $0.0001 ; \chi^{2}=22.28, \mathrm{df}=1, \mathrm{p}<0.0001$, respectively). Conversely, bait types least taken by $C$. taurus (squid and sardine) were taken more frequently by teleosts. This increase was significant for fishes targeting squid $\left(\chi^{2}=5.57, \mathrm{df}=1, \mathrm{p}=0.018\right)$, but not for those targeting sardine $\left(\chi^{2}=0.273, \mathrm{df}=1, \mathrm{p}=0.601\right)$.

The approaches of Carcharias taurus suggested an inquisitive, although cautious behaviour towards baited lines. Depredated baits were taken on the first approach on $33 \%$ of occasions, with an average of 2.5 ( $\pm 0.3 \mathrm{SE}$ ) non-depredation approaches before bait taking. Targeted depredation (where the shark actively approached the bait) accounted for over $92 \%$ of bait losses, with random encounters (where the bait drifted within $1 \mathrm{~m}$ of the shark before depredation) responsible for only $8 \%$ of baits consumed. There was no difference in time taken to depredate baits with either time of day $\left(\mathrm{ANOVA}_{i} \mathrm{MS}=0.117\right.$,
$F=0.160, \mathrm{p}=0.96)$, or $C$. taurus density (regression analysis; $\mathrm{MS}=8929, F=1.35, \mathrm{p}=0.25$ ).

\section{Horizontally towed lures}

A total of 625 replicated tows (390 shallow and 235 deep) were conducted almost equally across dawn $(\mathrm{n}=205)$, morning $(\mathrm{n}=210)$ and afternoon $(\mathrm{n}=210)$ around Fish Rock. The cumulative trolling distance was $537 \mathrm{~km}(333 \mathrm{~km}$ shallow and $204 \mathrm{~km}$ deep). Over 18750 fishes were observed during sampling (Table 2), although many of these were undoubtedly the same individuals sighted on multiple laps. There were 3630 instances of teleosts actively responding to towed lures (Table 2), with pelagic fishes (primarily Seriola lalandi) responsible in $95 \%$ of cases. The lures were struck by fish 132 times, although no fish were captured due to the disabled hooks. The large number of fish interactions suggests the gear was operating correctly.

Time of day was significant in explaining variability among the number of fish strikes, although this relationship was very weak $\left(\chi^{2}=6.05, \mathrm{df}=2, \mathrm{p}=\right.$ $0.049)$. Most strikes occurred during dawn ( $42 \%)$ and afternoon $(33 \%)$, with fewer interactions during mornings $(25 \%)$. On average, fish struck once every 3.6 shallow tows, but only once per 10.2 deep tows (Table 2). Only 1 Carcharias taurus was sighted during the $537 \mathrm{~km}$ of lure tows (Table 2), and this individual did not respond to the passing lure. Similarly, 2 C. taurus observed gulping air at the surface within

Table 2. Number of fish and Carcharias taurus sightings and interactions with towed attractants around Fish Rock, New South Wales, Australia. Shallow: 0-2 m depth; deep: 7-10 m depth

\begin{tabular}{|lcccccccc|}
\hline Lure type & Depth & $\begin{array}{c}\text { Varieties } \\
\text { tested }\end{array}$ & $\begin{array}{c}\text { No. of } \\
\text { replicates }\end{array}$ & $\begin{array}{c}\text { Fish } \\
\text { strikes }\end{array}$ & $\begin{array}{c}\text { Fish } \\
\text { reactions }\end{array}$ & $\begin{array}{c}\text { Fish } \\
\text { seen }\end{array}$ & $\begin{array}{c}\text { C. taurus } \\
\text { interactions }\end{array}$ & $\begin{array}{c}\text { C. taurus } \\
\text { seen }\end{array}$ \\
\hline Hard plastic & Shallow & 4 & 120 & 17 & 504 & 1098 & 0 & 0 \\
Hard plastic rattling & Deep & 4 & 115 & 14 & 868 & 7173 & 0 & 0 \\
& Shallow & 2 & 60 & 30 & 618 & 735 & 0 & 0 \\
Plastic popper & Deep & 2 & 60 & 7 & 305 & 1724 & 0 & 1 \\
& Shallow & 2 & 60 & 8 & 80 & 360 & 0 & 0 \\
Soft plastic & Deep & 0 & 0 & 0 & 0 & 0 & 0 & 0 \\
& Shallow & 2 & 60 & 31 & 541 & 1152 & 0 & 0 \\
Metal & Deep & 0 & 0 & 0 & 0 & 0 & 0 & 0 \\
& Shallow & 1 & 30 & 7 & 129 & 196 & 0 & 0 \\
Feather jig & Deep & 1 & 30 & 1 & 99 & 718 & 0 & 0 \\
\multirow{2}{*}{ Whole fish } & Shallow & 2 & 60 & 16 & 344 & 714 & 0 & 0 \\
& Deep & 0 & 0 & 0 & 0 & 0 & 0 & 0 \\
& Shallow & 0 & 0 & 0 & 0 & 0 & 0 & 0 \\
\hline
\end{tabular}


$20 \mathrm{~m}$ of the gear also showed no response to the passing attractant.

\section{Vertically deployed jigs}

Jigs were dropped and retrieved at an average of 8.1 times per 5 min replicate. A total of 977 individual jig drops were analysed, with 176 drops discarded (143 due to the absence of any Carcharias taurus and 33 due to gear issues). Of the remaining 801 successful drops, 63 (7.9\%) landed outside the area where the sharks were located, with the remaining $92.1 \%$ of drops landing within the same region as the sharks (i.e. within the same gutter). We believe these 738 proximate drops provide a realistic assessment of interaction potential when fishing around $C$. taurus aggregations.

Vertical jigs elicited little direct response from aggregations of Carcharias taurus. Jigs passed within a body length of a shark during $54 \%$ of proximate drops, resulting in only 6 attempts to bite the jigs (Table 3). Two of these attempts occurred immediately following the jig hitting the shark. Only 1 attempt to bite the jig produced contact with the jig, with the other attempts resulting in near misses. The jigs contacted a C. taurus in $5 \%$ of proximate drops. Of these, contact occurred $62 \%$ of time during deployment and $38 \%$ during retrieval (Table 3). Under conventional conditions, these drops may have incidentally hooked the sharks. There were also 25 instances (3\% of proximate drops) where the fishing line, or camera, contacted a shark without the jig touching, and a further 19 'near misses', where the jig passed within millimetres of the shark without making contact (Table 3). $C$. taurus was not observed chasing vertical jigs during deployment or retrieval, and interactions were restricted to individuals located close to the substratum.

Benthic-oriented jigs elicited little response from Carcharias taurus. In 60 replicates, sharks snapped at the jig 3 times, making contact once, and missing twice. Nevertheless, we observed 50 interactions be- tween C. taurus and the benthic-oriented jigs. Of these, $44 \%$ involved the shark actively rubbing alongside the jig, or bumping the jig with its head. Random contacts (where the jig drifted onto the shark) accounted for the other $56 \%$ of shark interactions with this jig type. Either form of contact may have resulted in foul hooking of the shark had the hooks not been disabled.

\section{DISCUSSION}

Our findings unequivocally demonstrate interactions between Carcharias taurus and particular recreational fishing gears deployed around aggregations of these sharks. The risk of $C$. taurus interacting with recreational fishing gears strongly depends on both the type of gear and its proximity to the substrate. All benthic-oriented gears had some potential to evoke a response from $C$. taurus, with baits posing the greatest risk. Pelagic gears, such as lures, do not pose such an immediate risk.

Carcharias taurus is a generalist feeder, although it preferentially targets larger teleosts and rays (Gelsleichter et al. 1999, Smale 2005). Selectivity of bait by size was observed in the present study, since the 2 largest baits (whole and filleted blue mackerel) were depredated at the greatest rates, whereas the smaller baits such as Australian sardine and squid were depredated less by C. taurus, while being taken more frequently by recreationally important fishes during daylight hours. Although this may appear a positive result of bait selectivity potentially reducing incidental shark capture, the relationship was not significant for sardine baits, and the rates at which C. taurus depredated these smaller bait types (3 to $15 \%$ ) remain unacceptably high to consider limiting fishing to such baits as a viable conservation strategy. Bait size did not alter the rate at which the whole and filleted blue mackerel baits were consumed by C. taurus, but it is possible that both blue mackerel bait types were sufficiently large to capture the sharks' interest.

Table 3. Carcharias taurus. Number of shark interactions with vertically deployed jigs at Fish Rock, New South Wales, Australia. Line touches include occasions where the fishing line or inline camera hit a shark

\begin{tabular}{|c|c|c|c|c|c|c|c|}
\hline Jig & $\begin{array}{c}\text { Time of } \\
\text { day }\end{array}$ & $\begin{array}{c}\text { Proximate } \\
\text { drops }\end{array}$ & $\begin{array}{l}\text { Contacts on } \\
\text { deployment }\end{array}$ & $\begin{array}{c}\text { Contacts on } \\
\text { retrieval }\end{array}$ & $\begin{array}{l}\text { Attempted } \\
\text { bites }\end{array}$ & $\begin{array}{l}\text { Line } \\
\text { touches }\end{array}$ & $\begin{array}{l}\text { Near } \\
\text { misses }\end{array}$ \\
\hline \multirow[t]{2}{*}{ Soft plastic } & Morning & 243 & 9 & 5 & 3 & 7 & 5 \\
\hline & Afternoon & 230 & 10 & 5 & 3 & 16 & 12 \\
\hline \multirow[t]{2}{*}{ Knife jig } & Morning & 125 & 1 & 2 & 0 & 1 & 2 \\
\hline & Afternoon & 140 & 3 & 2 & 0 & 1 & 0 \\
\hline
\end{tabular}


Although Carcharias taurus typically increase their movement at twilight and night (Bruce \& Stevens 2002), we found no corresponding positive correlation with rates of bait depredation. It is possible, however, that feeding events may have occurred outside our study area, given that these sharks can move greater distances from their daytime positions than we sampled (Bruce \& Stevens 2002). Nocturnal roaming outside the study area may also explain the lower bait depredation rates we observed at dawn and night. The lack of identifiable peaks in feeding activity precludes reducing accidental hooking risk by limiting fishing during discrete time periods. Nevertheless, because $C$. taurus was the only nocturnal bait depredator, restricting night fishing around $C$. taurus aggregations remains a potential management option to reduce their incidental capture.

Carcharias taurus displayed a predictable lack of response towards towed attractants. The towed lures and bait were only briefly visible to sharks at the bottom of rugous vertical gutters, and were moving relatively rapidly as they passed overhead. Although $C$. taurus have been sighted with trolling lures attached (Bansemer \& Bennett 2010), this may be an indirect effect of sharks predating on hooked teleosts such as Seriola lalandi. The low rate of this type of hooking interaction relative to other identifiable gears (4\%) supports this hypothesis (Bansemer \& Bennett 2010). Although our data suggest that using towed gear types around $C$. taurus aggregations is unlikely to have any direct impact on sharks, the suspected rate of indirect hooking may be reduced by fishers using heavier lines to ensure a more rapid retrieval of fish, and by targeting fishes higher in the water column.

Carcharias taurus also displayed minimal responses to vertically deployed jigs. Indeed, with the exception of a single attempted bite, our data showed that vertical jigs such as knife jigs and soft plastics must hit the shark to result in potential hooking. We hypothesise that hook penetrations would be greater during gear retrieval than deployment, as the taut fishing line would aid in 'setting' the hook. Fortunately, there were fewer interactions during jig retrieval. Jig fishing is presently permitted in critical habitats only while the vessel is drifting, and thus the likelihood of an interaction is limited to those occasions when fishing occurs directly above the shark. Although recreational fishers are invariably ignorant of the position of C. taurus aggregations within critical habitats, our findings suggest that vertically deployed jigs are less of a problem than other benthic fishing gears such as baited lines. Nevertheless, potential impacts may be reduced by fishers ensuring that jig descents are arrested prior to reaching the benthos.

Because we aimed to investigate the response of Carcharias taurus to recreational fishing gears, daytime bait and jig trials were conducted proximate $(<40 \mathrm{~m})$ to shark aggregations. Although shark density did not influence the time to take baits, it is likely that our sampling proximate to $C$. taurus aggregations represents greater levels of interaction than may occur when fishing at a distance. Nevertheless, we did not use attraction techniques such as burley, increased scent areas through multiple lines, 'live' baits, or having struggling hooked fishes on our lines. Recreational fishers commonly use such attracting processes, which might prompt a greater response from non-proximate C. taurus. The potential for fishing vessels to attract sharks in this way was demonstrated by Otway et al. (2009), who noted a telemetrytracked C. taurus responding to a recreational fishing vessel $1.2 \mathrm{~km}$ distant. Movements of this distance are considerably greater than the minimum radius of all current NSW critical habitat zones (DPI 2007).

The consequences of continued fishing interactions for the eastern Australian population of Carcharias taurus are potentially severe. Retained fishing gear or gear injury can reduce the ability of a shark to feed, and may lead to permanent deformities (Bansemer \& Bennett 2010). Although the external hooking rates are similar for immature and mature animals, the latter show a greater propensity for jaw injuries (Bansemer \& Bennett 2010). This may be due to their increased fighting capacity once hooked. The effects of such injuries have not been quantified, but would likely reduce the hunting fitness and survival of this reproductive part of the population. A number of hooked individuals were sighted during this study, with many appearing stressed. One such individual was observed flicking its head in an apparent attempt to dislodge fishing gear trailing out of its gill (W. Robbins pers. obs). Moreover, with autopsies of 8 incidentally killed NSW C. taurus revealing that $75 \%$ had suffered internal hook damage without external indications (Otway \& Burke 2004), it is possible that many of the apparently unhooked individuals sighted in this study would have similar internal injuries.

The east coast Carcharias taurus population was most recently estimated at 1146 to 1662 individuals (Lincoln Smith \& Roberts 2010). Although greater than previous estimates (Otway \& Burke 2004), this number is still well below the minimum viable population requirement based on current mortality and demographic rates (Bradshaw et al. 2008). Moreover, the incidental capture of local C. taurus still occurs 
via other means, including commercial fishing and inshore shark meshing programmes (Macbeth et al. 2009, Reid et al. 2011, Sumpton et al. 2011). The east Australian population is reproductively isolated from the Western Australian population (Stow et al. 2006), and is likely to remain so unless climatic conditions change to allow migrations around southern Australia (Bradshaw et al. 2008). Therefore current east coast management must focus on minimising detrimental anthropogenic interactions.

The issue of incidental fishing interactions is by no means unique to recreational fishing. Incidental capture of non-target species occurs in commercial line and net fisheries, where sharks and other species are often incidentally captured (Walker et al. 2005, Watson et al. 2005, Gilman et al. 2008). Programmes designed to protect swimmers from dangerous sharks (shark nets and drums) can similarly capture non-target species, including protected sharks, dolphins, turtles and whales (Green et al. 2009, Reid et al. 2011, Sumpton et al. 2011). Methods exist to reduce the incidental capture of unwanted species in these industries, including setting nets in depths and areas which reduce incidental interactions, employing marine mammal deterrent alarms and, in the case of commercial line fishing, using baits which are less attractive to non-target species (Williams \& Schaap 1992, Watson et al. 2005, Green et al. 2009).

The findings of our research suggest that prohibiting benthic-oriented fishing gears, especially baits, would similarly minimise recreational fishing interactions with Carcharias taurus aggregations. It is encouraging that as a result of this study, the NSW government has now prohibited the use of baits in all NSW critical habitats not located within marine parks, in an attempt to reduce $C$. taurus interactions (Allan 2012). However, benthic gears such as jigs are still permitted. Although management agencies are often asked to regulate fishing activities, selfmanagement inevitably provides more effective compliance to conserve species (Townsend et al. 2008). Recreational fishers should therefore be encouraged to participate in active measures to protect threatened species, particularly when their actions are considered instrumental in affecting the recovery of the species. In this case, the strong potential for a threatened species interaction with benthic fishing gear provides a proactive opportunity for recreational fishers to move from benthic-oriented fishing to pelagic trolling at $C$. taurus aggregation sites. Our finding of greater fish strike rates with surface-deployed lures suggests that such a move will not disadvantage fishers. Such efforts, in conjunction with the recent fish- ing regulation changes, should assist in the reduction of incidental hooking of $C$. taurus and its associated negative impacts.

Acknowledgements. This study was funded by a grant from the NSW Recreational Fishing Trust. Local fishers and dive operators provided on-ground assistance and advice. Numerous NSW DPI technicians provided valuable field assistance, while C. Vera Lopez provided laboratory assistance with video analyses. D. Collins guided the statistical analysis. We also thank the 3 anonymous reviewers for their helpful comments on this paper. This project was carried out under institutional Animal Care and Ethics approval (ACEC Ref 08/08).

\section{LITERATURE CITED}

Allan G (2012) Government gazette of the state of New South Wales. Special supplement. Section 8 notification grey nurse shark protection. Department of Premier and Cabinet, Sydney, p 4035-4036

Anderson RC, Ahmed H (1993) The shark fisheries of the Maldives. Ministry of Fisheries and Agriculture, Maldives, and FAO, Rome

Bansemer CS, Bennett MB (2009) Reproductive periodicity, localised movements and behavioural segregation of pregnant Carcharias taurus at Wolf Rock, southeast Queensland, Australia. Mar Ecol Prog Ser 374:215-227

Bansemer CS, Bennett MB (2010) Retained fishing gear and associated injuries in the east Australian grey nurse sharks (Carcharias taurus): implications for population recovery. Mar Freshw Res 61:97-103

Barker SM, Peddemors VM, Williamson JE (2011) Recreational SCUBA diver interactions with the critically endangered grey nurse shark Carcharias taurus. Pac Conserv Biol 16:261-269

Bascompte J, Melian CJ, Sala E (2005) Interaction strength combinations and the overfishing of a marine food web. Proc Natl Acad Sci USA 102:5443-5447

Bradshaw CJA, Peddemors VM, McAuley RB, Harcourt RG (2008) Population viability of eastern Australia grey nurse sharks under fishing mitigation and climate change. Final report to the Commonwealth of Australia, Department of the Environment, Water, Heritage and the Arts. The University of Adelaide, Adelaide

Bruce BD, Stevens JD (2002) Acoustic tracking of grey nurse sharks at Flat Rock, southern Queensland. Report to Queensland Parks and Wildlife Service. CSIRO Marine Research, Hobart

Compagno LJV (2001) Sharks of the world. An annotated and illustrated catalogue of shark species known to date. Vol 2. Bullhead, mackerel and carpet sharks (Heterodontiformes, Lamniformes and Orectolobiformes). FAO Species Catalogue for Fishery Purposes No 1, Vol 2. FAO, Rome

Cortés E (1999) Standardized diet compositions and trophic levels of sharks. ICES J Mar Sci 56:707-717

Cropp B (1964) Shark hunters. Rigby Limited, Adelaide

DPI (Department of Primary Industries) (2007) Protecting the grey nurse shark - a guide for recreational fishers and divers. NSW Department of Primary Industries, Sydney 
Gelsleichter J, Musick JA, Nichols S (1999) Food habits of the smooth dogfish, Mustelus canis, dusky shark, Carcharhinus obscurus, Atlantic sharpnose shark, Rhizoprionodon terraenovae, and the sand tiger, Carcharias taurus, from the northwest Atlantic Ocean. Environ Biol Fishes 54:205-217

Gilman E, Clarke S, Brothers N, Alfaro-Shigueto J and others (2008) Shark interactions in pelagic longline fisheries. Mar Policy 32:1-18

Green M, Ganassin C, Reid DD (2009) Report into the NSW shark meshing (bather protection) program. NSW Department of Primary Industries, Sydney

Lincoln Smith M, Roberts C (2010) Development and implementation of a population estimation protocol to provide an estimate of east coast population numbers for grey nurse sharks (Carcharias taurus). Stage 2 report for the Department of the Environment, Water, Heritage and the Arts. Cardno Ecology Lab, Sydney

Lucifora LO, Menni RC, Escalante AH (2002) Reproductive ecology and abundance of the sand tiger shark, Carcharias taurus, from the southwestern Atlantic. ICES J Mar Sci 59:553-561

Macbeth WG, Geraghty PT, Peddemors VM, Gray CA (2009) Observer-based study of targeted commercial fishing for large shark species in waters off northern New South Wales. Industry \& Investment NSW, Sydney Myers RA, Worm B (2003) Rapid worldwide depletion of predatory fish communities. Nature 423:280-283

Myers RA, Baum JK, Shepherd TD, Powers SP, Peterson CH (2007) Cascading effects of the loss of apex predatory sharks from a coastal ocean. Science 315:1846-1850

Otway NM, Burke AL (2004) Mark-recapture population estimate and movements of grey nurse sharks. Final Report to Environment Australia, project no. 30786/87. New South Wales Fisheries Final Report Series No. 63, Sydney

Otway NM, Bradshaw CJA, Harcourt RG (2004) Estimating the rate of quasi-extinction of the Australian grey nurse shark (Carcharias taurus) population using deterministic age- and stage-classified models. Biol Conserv 119: 341-350

Otway NM, Ellis MT, Louden BM, Gilligan JJ (2009) Documentation of depth related migratory movements, localised movements at Critical Habitat sites and the effects of scuba diving for the east coast grey nurse shark population. Fisheries Final Report Series No. 112, Industry and Investment New South Wales, Sydney

Preacher KJ (2001) Calculation for the chi-square test: an interactive calculation tool for chi-square tests of goodness of fit and independence. Available at http://quant psy.org (accessed 15 October 2012)

R Development Core Team (2012) R: a language and environment for statistical computing. R Foundation for Statistical Computing, Vienna. Available at www.R-project. org

Editorial responsibility: Cornelius Hammer, Rostock, Germany
Reid DD, Robbins WD, Peddemors VM (2011) Decadal trends in shark catches and effort from the New South Wales, Australia Shark Meshing Program 1950 to 2010. Mar Freshw Res 62:676-693

Robbins WD, Hisano M, Connolly SR, Choat JH (2006) Ongoing collapse of coral reef shark populations. Curr Biol 16:2314-2319

Robbins WD, Peddemors VM, Kennelly SK (2011) Assessment of permanent magnets and electropositive metals to reduce the line-based capture of Galapagos sharks, Carcharhinus galapagensis. Fish Res 109:100-106

> Smale MJ (2005) The diet of the ragged-tooth shark Carcharias taurus Rafinesque 1810 in the Eastern Cape, South Africa. Afr J Mar Sci 27:331-335

Smith SE, Au DW, Show C (1998) Intrinsic rebound potentials of 26 species of Pacific sharks. Mar Freshw Res 49: 663-678

- Stevens JD, Bonfil R, Dulvy NK, Walker PA (2000) The effects of fishing on sharks, rays, and chimaeras (chondrichthyans), and the implications for marine ecosystems. ICES J Mar Sci 57:476-494

> Stow A, Zenger K, Briscoe D, Gillings M, Peddemors VM, Otway NM, Harcourt R (2006) Isolation and genetic diversity of endangered grey nurse shark (Carcharias taurus) populations. Biol Lett 2:308-311

Sumpton WD, Taylor SM, Gribble NA, McPherson GL, Ham T (2011) Gear selectivity of large-mesh nets and drumnlines used to catch sharks in the Queensland Shark Control Program. Afr J Mar Sci 33:37-43

Takeuchi Y, Senba Y, Nakano H (2005) Demographic analysis on Atlantic blue and shortfin mako sharks. Collect Vol Sci Pap ICCAT 58:1157-1165

Townsend R, Shotton R, Uchida H (2008) Case studies in fisheries self-governance. FAO Fish Tech Pap 504. FAO, Rome

- Walker TI (1998) Can shark resources be harvested sustainably? A question revisited with a review of shark fisheries. Mar Freshw Res 49:553-572

Walker TI, Hudson RJ, Gason AS (2005) Catch evaluation of target, by-product and by-catch species taken by gillnets and longlines in the shark fishery of south-eastern Australia. J Northwest Atl Fish Sci 35:505-530

- Ward P, Myers RA (2005) Shifts in open-ocean fish communities coinciding with the commencement of commercial fishing. Ecology 86:835-847

> Watson JW, Epperly SP, Shah AK, Foster DG (2005) Fishing methods to reduce sea turtle mortality associated with pelagic longlines. Can J Fish Aquat Sci 62:965-981

Williams H, Schaap AH (1992) Preliminary results of a study into the incidental mortality of sharks in gill-nets in two Tasmanian shark nursery areas. Aust J Mar Freshw Res 43:237-250

> Worm B, Barbier EB, Beaumont N, Duffy JE and others (2006) Impacts of biodiversity loss on ocean ecosystem services. Science 314:787-790

Submitted: December 17, 2012; Accepted: May 22, 2013 Proofs received from author(s): July 11, 2013 